\title{
MyD88-dependent and independent pathways of Toll-Like Receptors are engaged in biological activity of Triptolide in ligand-stimulated macrophages
}

\author{
Vummidigiridhar Premkumar ${ }^{\dagger 1}$, Moul Dey*+2, Ruth Dorn ${ }^{3}$ and llya Raskin 3
}

\begin{abstract}
Background: Triptolide is a diterpene triepoxide from the Chinese medicinal plant Tripterygium wilfordii Hook F., with known anti-inflammatory, immunosuppressive and anti-cancer properties.

Results: Here we report the expression profile of immune signaling genes modulated by triptolide in LPS induced mouse macrophages. In an array study triptolide treatment modulated expression of $22.5 \%$ of one hundred and ninety five immune signaling genes that included Toll-like receptors (TLRs). TLRs elicit immune responses through their coupling with intracellular adaptor molecules, MyD88 and TRIF. Although it is known that triptolide inhibits NFkB activation and other signaling pathways downstream of TLRs, involvement of TLR cascade in triptolide activity was not reported. In this study, we show that triptolide suppresses expression of proinflammatory downstream effectors induced specifically by different TLR agonists. Also, the suppressive effect of triptolide on TLR-induced NFKB activation was observed when either MyD88 or TRIF was knocked out, confirming that both MyD88 and TRIF mediated NFKB activation may be inhibited by triptolide. Within the TLR cascade triptolide downregulates TLR4 and TRIF proteins.
\end{abstract}

Conclusions: This study reveals involvement of TLR signaling in triptolide activity and further increases understanding of how triptolide activity may downregulate NFKB activation during inflammatory conditions.

\section{Background}

Chronic inflammation is an important patho-physiological condition impacting various diseases including rheumatoid arthritis (RA), atherosclerosis, diabetes, and cancer. Recent evidence suggests the involvement of Tolllike receptors (TLRs) in various chronic inflammatory and autoimmune diseases [1-3]. TLRs belong to the family of pathogen-associated molecular pattern recognition receptors and are vital components of the host's immune system for sensing dangerous pathogens, and for initiating inflammatory and immune responses directed against these pathogens. The mechanism of signal transduction through TLRs is well characterized [4-11]. There are two possible routes for mediation of signals received by TLRs

\footnotetext{
* Correspondence: moul.dey@sdstate.edu

2 Nutrigenomics Program, South Dakota State University, Brookings, SD 57007, USA

+ Contributed equally

Full list of author information is available at the end of the article
}

depending on which of the two adapter molecules (MyD88 and TRIF) are involved. The importance of MyD88 and TRIF lies in the finding that each leads to a distinct profile of immune mediators that in turn determine the phenotype of the cells that are primarily responsible for the development of adaptive immune responses [1-4]. TLR4 mediates through both the MyD88 and TRIF pathways, TLR3 signals through TRIF and all the other TLRs mediate through MyD88 pathway [5-8]. Characterization of cellular responses to various ligands that selectively activate specific TLRs is not only useful in better understanding of disease pathogenesis but can also potentially help identify molecular targets by which pharmacological compounds modulate TLR-mediated signaling pathways and target gene expression.

Triptolide is a biologically active diterpene triepoxide from a Chinese herb Tripterygium wilfordii Hook F, commonly known as thunder god vine. Extracts from this 
plant have been historically used in traditional Chinese medicine to treat inflammatory and autoimmune diseases such as rheumatoid arthritis, systemic lupus, psoriatic arthritis and Behcet's disease [12]. Triptolide inhibited the expression of proinflammatory markers including COX-2 and iNOS in RAW macrophage [13]. Triptolide suppressed c-jun $\mathrm{NH}_{2}$-terminal kinase (JNK) phosphorylation, COX-2 expression and PGE2 production in microglial cultures treated with lipopolysaccharide [14]. NFkB activation due to inflammatory response in chronic diseases is well characterized [15]. Existing reports demonstrate the effect of triptolide on NFKB activation and target gene expression as well as its effect on other transcription factors [16]. Although TLRs are known to impact downstream NFKB activation [17], effects of triptolide in TLR signaling have not been evaluated. In this study we investigated the effects of triptolide activity on receptors and target gene expression induced by activation of TLRs.

\section{Methods}

\section{Chemicals and biochemicals}

Antibiotics, Dimethyl sulphoxide (DMSO), triptolide (MW 360.4) and LPS (lipopolysaccharide from E.coli, serotype 055:B5) were purchased from Sigma chemicals (St. Louis, MO). Ligands for TLR2 (Zymosan) and TLR3 (Poly I:C) were purchased from Invivogen (San Diego, CA). Cell culture media were obtained from Invitrogen Inc. (Carlsbad, CA). Reagents used in quantitative PCR, including enzymes MyD88 and TRIF pre-designed siRNA purchased from Ambion (Austin, TX). RAW 264.7 cell line (ATCC TIB-71) was provided by American Type Culture Collection (Manassas, VA). The BCA Protein Assay kit and NE-PER Extraction kit were obtained from Pierce (Rockford, IL). The ECL Advanced Western blotting detection Kit chemiluminescence system from Amersham Biosciences (Buckinghamshire, UK). Broad ranger blotting markers, anti-TLR4 rabbit polyclonal antibody, anti-actin rabbit polyclonal antibody and Horseradish peroxidase-conjugated anti-rabbit antibody were purchased from Santa Cruz Biotechnology, Inc. (Santa Cruz, CA). Anti-TRIF rabbit polyclonal antibody was purchased from Cell Signaling Technology (Beverly, MA)

\section{Macrophage cell culture assay}

RAW 264.7 macrophage cells were cultured as described by Dey et al., 2006 [18]. Briefly, cells were seeded at a density of $0.4 \times 10^{6}$ cells per well (viable cell counts were carried out by trypan blue staining using a hemocytometer) in 24-well plates $12 \mathrm{~h}$ prior to treatment. The cells were then treated with triptolide dissolved in DMSO at concentration (per ml of cells) of $20 \mathrm{ng}, 10 \mathrm{ng}, 5 \mathrm{ng}$ and $1 \mathrm{ng}$ for $2 \mathrm{~h}$ before elicitation with bacterial endotoxin LPS (lipo-polysaccharide from E.coli, serotype 055:B5) at 1 $\mu \mathrm{g} / \mathrm{ml}$ for TLR-4 elicitation, Zymosan at $1 \mathrm{ug} / \mathrm{ml}$ for TLR2 elicitation and Poly I:C (synthetic analog of dsRNA) at $10 \mathrm{ug} / \mathrm{ml}$ for TLR-3 elicitation. The corresponding molar concentrations of triptolide (MW 360.4) that are used in Figures 1, 2, 3, 4 and 5 were $55.5 \mathrm{nM}, 27.7 \mathrm{nM}, 13.8 \mathrm{nM}$ and $2.7 \mathrm{nM}$ respectively. For each experiment, one positive control (cells treated with ligands and vehicle) and one negative control (cells treated with vehicle only) were included. For RNA extraction, the cells were harvested in TRIzol after $6 \mathrm{~h}$ of ligand stimulation and for protein expression the cells were harvested after $12 \mathrm{~h}$. Two replicates were made for all the treatments and their controls. The concentrations of triptolide used were previously tested to be non-cytotoxic using a MTT assay [13]. The $\mathrm{CC}_{50}$ (concentration at which $50 \%$ of cells remain viable) of triptolide for macrophages is $\sim 83.2 \mathrm{nM}$.

\section{MyD88KO and TRIFKO using RNAi}

Pre-designed small interfering RNA (siRNA) oligonucleotides targeting endogenous MyD88 and TRIF were purchased from Ambion (Austin, TX). The siRNA duplexes were transfected using lipofectamine 2000 (Invitrogen) into RAW 264.7 cells following the manufacturer's protocol. Briefly, cells were plated at $0.2 \times 10^{6} \mathrm{cell} /$ well in a $24-$ well plate maintained in Dulbecco's modified Eagle's medium (DMEM) supplemented with 10\% heat-inactivated fetal bovine serum. After $24 \mathrm{~h}$, cells were treated with $1 \mu \mathrm{l}$ of $50 \mu \mathrm{M}$ MyD88-siRNA or TRIF-siRNA in a transfection mixture containing lipofectamine 2000 and incubated in $5 \% \mathrm{CO}_{2}$, at $37^{\circ} \mathrm{C}$. After $24 \mathrm{~h}$ of transfection the medium was changed with $1 \mathrm{ml}$ of fresh DMEM. Two hours before elicitation with LPS $(1 \mu \mathrm{g} / \mathrm{mL})$, the cells were treated with predetermined doses of triptolide. For RNA extraction, the cells were harvested in TRIzol after 6 $\mathrm{h}$ of treatment and for protein expression the cells were harvested after $12 \mathrm{~h}$.

\section{Total RNA extraction, purification, and CDNA synthesis}

Total RNA extraction, purification and cDNA synthesis were performed following procedures described in Dey $e t$ al., 2006 [18].

\section{Quantitative polymerase chain reaction and gene array}

qRT-PCR was performed as described by Dey et al., 2006 [18]. Gene-specific primers (synthesized by IDT Inc., Coralville, IA) used in the current study are described in Table 1. For the gene array experiment, PCR-arrays (APM_025, SABiosciences, MD) were purchased and the manufacturer's protocol was followed. Relative quantification based on SYBR green was used for individual and gene array experiments.

\section{Immunoblotting analysis of TRIF and TLR4}

The cells were lysed using RIPA buffer (Pierce, Rockford, IL) according to the manufacturer's protocol. Equal 
Table 1: Sequence of primers used for real time RT-PCR.

\begin{tabular}{|c|c|c|}
\hline Gene symbol* (accession\#) & Forward primer & Reverse primer \\
\hline$\beta$-actin (NM 007393) & 5'AACCGTGAAAAGATGACCCAGAT3' & 5'CACAGCCTGGATGGCTACGT3' \\
\hline COX-2 (NM 011198) & 5'TGGTGCCTGGTCTGATGATG3' & 5'GTGGTAACCGCTCAGGTGTTG3' \\
\hline iNOS ( & 5'CCCTCCTGATCTTGTGTTGGA3' & 5'TCAACCCGAGCTCCTGGAA3' \\
\hline MyD88 (NM 010851) & 5'TGGCCTTGTTAGACCGTGA3' & 5'AAGTATTTCTGGCAGTCCTCCTC3' \\
\hline TRIF (NM 174989) & 5'TGGCAAACACCTTCAAGACA3' & 5'GCGCTTTCTTCCAGCGTA3' \\
\hline CCL3 (NM 011337) & 5'TGCCCTTGCTGTTCTTCTCT3' & 5'GTGGAATCTTCCGGCTGTAG3' \\
\hline IRG1 (M 008392) & 5'GCTITTGTTAATGGTGTTGCTG3' & 5'GGCTTCCGATAGAGCTGTGA3' \\
\hline TLR2 (NM 011905) & 5'GGGGCTTCACTTCTCTGCTT3' & 5'AGCATCCTCTGAGATTTGACG3' \\
\hline TLR3 (NM 126166) & 5'GATACAGGGATTGCACCCATA3' & 5'TCCCCCAAAGGAGTACATTAGA3' \\
\hline TLR4 (NM 021297) & 5'GGACTCTGATCATGGCACTG3' & 5'CTGATCCATGCATTGGTAGGT3' \\
\hline
\end{tabular}

*Refer to abbreviation list for full gene names

amounts of total cellular protein $(20 \mu \mathrm{g})$ was quantified using BCA protein assay kit according to the kit's protocol. The samples were resolved by $10 \%$ SDS-PAGE under reducing conditions $(100 \mathrm{~V}, 2 \mathrm{~h})$ and transferred to nitrocellulose membranes $(50 \mathrm{~V}, 2 \mathrm{~h})$ in a buffer consisting of $20 \% \mathrm{v} / \mathrm{v}$ methanol, $200 \mathrm{mM}$ Glycine, $25 \mathrm{mM}$ Tris, pH 8.3. The membrane was blocked for overnight at $4^{\circ} \mathrm{C}$ and then incubated with anti-TRIF rabbit polyclonal antibody $(1: 1000)$ or anti-TLR4 rabbit polyclonal antibody $(1: 1000)$ or anti-actin rabbit polyclonal antibody (1:5000) for $2 \mathrm{~h}$ at RT. Horseradish peroxidase-conjugated secondary antirabbit antibody was used and incubated for $1 \mathrm{~h}$ at RT. Immunodetection was performed using an ECL Advanced Western blotting detection Kit chemiluminescence system. The autoradiograms were quantified using scanning densitometry (Total Labs software v 2.01).

\section{Cell fractionation and transactivation of NFKB (p65)}

Nuclear extracts were prepared according to the instructions provided in NE-PER ${ }^{\mathrm{mm}}$ Pierce Nuclear and Cytoplasmic extraction kit). Cells were collected 45 minutes after LPS induction $(1 \mu \mathrm{g} / \mathrm{ml})$. A $50 \mu \mathrm{g}$ amount of nuclear extracts from macrophage cells were electrophoresed in $12 \%$ SDS-PAGE under reducing conditions, transferred to nitrocellulose membranes and blocked with $5 \%$ Nonfat milk powder in PBS. Membranes were incubated with rabbit polyclonal antibodies to p65 (1/500) or anti-actin. Secondary anti-rabbit peroxidase bound antibody was used. The immunodetection was performed using an ECL Advanced western blotting detection Kit chemiluminescence system. The autoradiograms were quantified using scanning densitometry (Total Labs software v 2.01).

\section{Statistical analysis}

The data are expressed as Mean \pm Standard Deviation (SD). Statistical significance for the data for mRNA and densitometric analysis were calculated using analysis of variance (ANOVA) and the group means were compared by the least significant difference test (LSD). The results were considered statistically significant if $p<0.05$.

\section{Results}

Gene array data confirmed known and revealed unknown genes affected by triptolide

Expression of one hundred and ninety five target genes in response to triptolide treatment were studied by gene array in LPS stimulated mouse macrophages. The genes based on their response to LPS stimulation were characterized as LPS-responsive (Table 2) and LPS-nonresponsive genes (Table 3). Among LPS-responsive genes, 42 genes were downregulated (Table a2a) and 2 genes (Table b2b) were upregulated by triptolide treatment. Fourteen genes were found to be non-responsive to LPS induction (Table 3). Of these non-responsive genes, 8 genes were downregulated (Table a3a) and 6 genes were upregulated by triptolide treatment (Table b3b). Huang et al. (2006) reported that 320 genes were upregulated in RAW 264.7 cells in response to LPS treatment but only $32(10 \%)$ genes were downregulated by triptolide [19]. In our study that included some overlapping genes with Huang et al (2006) [19], triptolide down regulated $21 \%$ of the LPSinduced genes and affected a total of $22.5 \%$ of LPSresponsive genes (including down and upregulations) in RAW macrophages. Triptolide treatment was found to downregulate the expression of TLRs 1 and 4 (Table a2a), TLRs 3 and 7 (Table a3a), TNF, IL-6, IL-1, NFkB1, MAPK, Rel, Bcl3, COX-2 (Table a2a) and other important inflammation regulating genes (Tables $2,3,4$ ). The gene array results obtained for COX-2, TNF $\alpha, \operatorname{IL} 1 \beta$ (data not shown) and TLR4 were further validated using qRT-PCR. We further investigated expression of TLR-mediated genes to understand in greater details the extent of 
Table 2: Fold changes in gene expression in cells treated with triptolide $(55.5 \mathrm{nM})+\mathrm{LPS}(1 \mu \mathrm{g} / \mathrm{ml})$ as compared to those treated with LPS $(1 \mathrm{\mu g} / \mathrm{ml})$ alone.

a) Downregulation of LPS- stimulated genes by triptolide.

\begin{tabular}{|c|c|c|c|c|}
\hline \multirow{2}{*}{$\begin{array}{l}\text { Gene } \\
\text { Symbol }\end{array}$} & \multirow[t]{2}{*}{ Accession No. } & \multirow[t]{2}{*}{ Gene name } & \multicolumn{2}{|c|}{ Fold change in response to treatment } \\
\hline & & & LPS* & LPS+triptolide \\
\hline $\mathrm{Ccl} 2$ & NM 011333 & Chemokine ( $\mathrm{C}-\mathrm{C}$ motif) ligand 2 & 19.90 & -11.98 \\
\hline $\mathrm{Ccl} 22$ & NM 011331 & Chemokine (C-C motif) ligand 12 & 692.18 & -8.53 \\
\hline $\mathrm{Ccl} 3$ & NM 011337 & Chemokine ( $\mathrm{C}-\mathrm{C}$ motif) ligand 3 & 4.48 & -3.82 \\
\hline $\mathrm{Ccl} 5$ & $\underline{\text { NM } 013653}$ & Chemokine ( $\mathrm{C}-\mathrm{C}$ motif) ligand 5 & 22.86 & -19.05 \\
\hline $\mathrm{Ccl} 7$ & NM 013654 & Chemokine ( $\mathrm{C}-\mathrm{C}$ motif) ligand 7 & 96.67 & -19.73 \\
\hline Ccl9 & NM 011338 & Chemokine ( $\mathrm{C}-\mathrm{C}$ motif) ligand 9 & 77.98 & -30.74 \\
\hline Cxcl10 & NM 021274 & Chemokine (C-X-C motif) ligand 10 & 113.38 & -39.18 \\
\hline Cxcl11 & NM 019494 & Chemokine (C-X-C motif) ligand 11 & 41.50 & -13.01 \\
\hline$\| 10$ & NM 010548 & Interleukin 10 & 55.52 & -47.24 \\
\hline Il10ra & NM 008348 & Interleukin 10 receptor, alpha & 4.01 & -3.21 \\
\hline Il13ra1 & NM 133990 & Interleukin 13 receptor, alpha 1 & 13.13 & -11.17 \\
\hline 1118 & $\underline{N M \quad 008360}$ & Interleukin 18 & 17.33 & -7.68 \\
\hline Il1a & NM 010554 & Interleukin 1 alpha & 2360.70 & -102.68 \\
\hline $111 b$ & $\underline{N M \quad 008361}$ & Interleukin 1 beta & 1140.14 & -55.02 \\
\hline II1f6 & NM 019450 & Interleukin 1 family, member 6 & 51.09 & -39.18 \\
\hline $112 \mathrm{rg}$ & NM 013563 & Interleukin 2 receptor, gamma chain & 15.73 & -5.66 \\
\hline Itgam & $\underline{N M \quad 008401}$ & Integrin alpha $\mathrm{M}$ & 7.09 & -5.91 \\
\hline Itgb2 & NM 008404 & Integrin beta 2 & 3.82 & -4.63 \\
\hline Spp1 & $\underline{\text { NM } 009263}$ & Secreted phosphoprotein 1 & 5.60 & -3.25 \\
\hline Tgfb1 & NM 011577 & Transforming growth factor, beta 1 & 4.27 & -1161.68 \\
\hline Tnf & NM 013693 & Tumor necrosis factor & 58.69 & -45.32 \\
\hline Tnfrsf1b & $\underline{\text { NM } 011610}$ & $\begin{array}{l}\text { Tumor necrosis factor receptor superfamily, } \\
\text { member } 1 \mathrm{~b}\end{array}$ & 90.82 & -16.94 \\
\hline $\mathrm{Bcl} 3$ & NM 033601 & B-cell leukemia/lymphoma 3 & 20.51 & -20.30 \\
\hline Crebbp & $\underline{\text { NM } 001025432}$ & CREB binding protein & 2.92 & -4.33 \\
\hline Csf2 & $\underline{\text { NM } 009969}$ & $\begin{array}{l}\text { Colony stimulating factor } 2 \text { (granulocyte- } \\
\text { macrophage) }\end{array}$ & 116.81 & -61.53 \\
\hline Csf3 & $\underline{\text { NM } 009971}$ & Colony stimulating factor 3 (granulocyte) & 13568.7 & -355.41 \\
\hline Gja1 & NM 010288 & Gap junction membrane channel protein alpha 1 & 4.65 & -6.20 \\
\hline 116 & NM 031168 & Interleukin 6 & 674.65 & -256.59 \\
\hline Nfkb1 & NM 008689 & $\begin{array}{l}\text { Nuclear factor of kappa light chain gene } \\
\text { enhancer in B-cells } 1 \text {, p105 }\end{array}$ & 32.63 & -3.37 \\
\hline Nfkbia & $\underline{\text { NM } 010907}$ & $\begin{array}{l}\text { Nuclear factor of kappa light chain gene } \\
\text { enhancer in B-cells inhibitor, alpha }\end{array}$ & 18.87 & -2.93 \\
\hline Rel & NM 009044 & Reticuloendotheliosis oncogene & 114.40 & -14.86 \\
\hline Ripk1 & $\underline{\text { NM } 009068}$ & $\begin{array}{l}\text { Receptor (TNFRSF)-interacting serine-threonine } \\
\text { kinase } 1\end{array}$ & 3.18 & -7.80 \\
\hline TIr1 & NM 030682 & Toll-like receptor 1 & 43.35 & -18.55 \\
\hline Tlr4 & $\underline{\text { NM } 021297}$ & Toll-like receptor 4 & 3.27 & -5.40 \\
\hline Tnfaip3 & NM 009397 & Tumor necrosis factor, alpha-induced protein 3 & 56.41 & -5.15 \\
\hline Cd14 & $\underline{\text { NM } 009841}$ & CD14 antigen & 4.01 & -7.56 \\
\hline
\end{tabular}


Table 2: Fold changes in gene expression in cells treated with triptolide ( $55.5 \mathrm{nM})+\mathrm{LPS}(1 \mu \mathrm{g} / \mathrm{ml})$ as compared to those treated with LPS ( $1 \mu \mathrm{g} / \mathrm{ml}$ ) alone. (Continued)

\begin{tabular}{|c|c|c|c|c|}
\hline Cd86 & NM 019388 & CD86 antigen & 4.24 & -2.90 \\
\hline Ifnb1 & NM 010510 & Interferon beta 1, fibroblast & 5.56 & -7.15 \\
\hline Irf3 & NM 016849 & Interferon regulatory factor 3 & 3.02 & -58.79 \\
\hline Ly86 & $\underline{\text { NM } 010745}$ & Lymphocyte antigen 86 & 5.15 & -8.21 \\
\hline Mapk8 & NM 016700 & Mitogen activated protein kinase 8 & 5.68 & -11.06 \\
\hline Ptgs2 & NM 011198 & Prostaglandin-endoperoxide synthase 2 & 566.13 & -51.89 \\
\hline
\end{tabular}

b) Upregulation of LPS down regulated genes by triptolide.

\begin{tabular}{lllr}
\hline $\begin{array}{l}\text { Gene } \\
\text { symbol }\end{array}$ & Accession No. & Gene Name & Fold change in response to treatment \\
& & & LPS+triptolide \\
& & & 4.02 \\
Smad3 & NM 016769 & MAD homolog 3 (Drosophila) & -13.20 \\
Mapk8ip3 & NM 013931 & $\begin{array}{l}\text { Mitogen-activated protein kinase 8 interacting } \\
\text { protein 3 }\end{array}$ &
\end{tabular}

* Fold changes for LPS treatments were determined by comparing to base level expressions in untreated cells

Positive values $(\geq+3)$ indicate stimulation while negative values $(\leq-3)$ represent suppression of gene expression.

involvement of TLR signaling cascade in the activity of triptolide.

\section{Effect of triptolide on downstream effector expression induced by TLR ligands}

There are three possible routes through which TLR signaling is mediated [5-8]. These routes either involve the adapter molecule MyD88, TRIF or both. TLR3 signals through TRIF and all other TLRs mediate through MyD88 pathway whereas TLR4 utilizes both MyD88 and TRIF to transduce the signal it receives [5-8]. One of the important readouts of TLR ligand induction is a robust pro-inflammatory response such as an upregulated expression/secretion of chemokines and cytokines. Using this modulation of chemokines/cytokine expression during different ligand induction the response to triptolide treatment was evaluated. Triptolide inhibited the expression of COX-2 and iNOS induced by MyD88- specific ligand - Zymosan (TLR2), TRIF- specific ligand, Poly I:C (TLR3) and LPS (TLR4) which activates both MyD88 and TRIF pathways (Figure 1). Downregulation of COX-2 and iNOS by triptolide [13] along with selected cytokines/ chemokines that are specific to each route of TLR signaling have been used to validate downstream effects of triptolide along the TLR pathway. COX-2 and iNOS expression is common to both MyD88-dependent and independent (TRIF) signaling pathways. The expression of CCL3 is specific for MyD88-dependent pathway and expression of IRG-1 is a specific readout of the TRIFdependent pathway [20-22]. Triptolide inhibited the expression of CCL3 in macrophage induced with Zymo- san (MyD88 specific ligand) and LPS (TLR4 specific but utilizes both TRIF and MyD88) (Figure 1A and Figure 1C). Triptolide also inhibited the expression of IRG-1 in macrophages induced with Poly I:C (TRIF specific ligand) and LPS (Figure 1B and Figure 1C). These results demonstrate that triptolide inhibits the activation of chemokines involved in both MyD88 and TRIF dependent pathways.

\section{Effect of triptolide on MyD88KO and TRIFKO in RAW cells induced with LPS}

To further validate the effect of triptolide on inflammatory pathways of MyD88 and TRIF, we evaluated the effect of triptolide on LPS induced macrophage under the two following scenarios: (1) MyD88 mediated pathway in the absence of TRIF regulation and (2) TRIF mediated pathway in the absence of MyD88 regulation. As both MyD88 and TRIF signaling pathways lead to NFkB activation [8], we determined the activity of triptolide on $\mathrm{NFkB}$ translocation to the nucleus (Figure 2). Also, because COX-2 and iNOS are downstream target genes regulated by $\mathrm{NF \kappa B}$, their increased expression is an indirect indicator of $\mathrm{NF}_{\mathrm{K}} \mathrm{B}$ activation. To further validate results of Figure 1, whether or not triptolide modulates both MyD88 and TRIF mediated signaling pathways, the activation of $\mathrm{NFKB}$ and the expression of COX-2 and iNOS induced by LPS in MYD88-KO macrophages and TRIF-KO macrophages were determined. Triptolide suppressed LPS-induced NFKB translocation in a dose dependent manner as determined by immunoblotting of the p65 protein in nuclear extracts. We observed that the incubation of MyD88-KO and TRIF-KO macrophages 
Table 3: Fold changes in gene expression in cells treated with triptolide ( $55.5 \mathrm{nM}$ ) as compared to endogenous expression levels in untreated cells.

a) Downregulation (s-3) of LPS-non responsive genes by triptolide.

\begin{tabular}{|c|c|c|c|}
\hline Gene symbol & Accession No. & Gene Name & $\begin{array}{l}\text { Fold change in response to } \\
\text { triptolide }\end{array}$ \\
\hline $\mathrm{Bcl} 6$ & NM 009744 & B-cell leukemia/lymphoma 6 & -5.36 \\
\hline Cxcr3 & NM 009910 & Chemokine (C-X-C motif) receptor 3 & -7.63 \\
\hline Tnfrsf1a & NM 011609 & $\begin{array}{l}\text { Tumor necrosis factor receptor } \\
\text { superfamily, member } 1 \mathrm{a}\end{array}$ & -5.18 \\
\hline Eif2ak2 & NM 011163 & $\begin{array}{l}\text { Eukaryotic translation initiation factor } \\
\text { 2-alpha kinase } 2\end{array}$ & -4.51 \\
\hline Tlr3 & NM 126166 & Toll-like receptor 3 & -10.73 \\
\hline Tlr7 & NM 133211 & Toll-like receptor 7 & -12.85 \\
\hline Ly96 & NM 016923 & Lymphocyte antigen 96 & -4.28 \\
\hline Map2k4 & NM 009157 & $\begin{array}{l}\text { Mitogen activated protein kinase kinase } \\
4\end{array}$ & -3.01 \\
\hline
\end{tabular}

b) Upregulation ( $\geq+3$ ) of LPS-non responsive genes by triptolide.

\begin{tabular}{llll}
\hline Gene symbol & Accession No. & Gene Name & $\begin{array}{l}\text { Fold change in response to } \\
\text { triptolide }\end{array}$ \\
\hline Ccl25 & NM 009138 & Chemokine (C-C motif) ligand 25 & 6.05 \\
Fasl & $\underline{\text { NM } 010177}$ & Fas ligand (TNF superfamily, member 6) & 115.09 \\
Irf1 & $\underline{\text { NM } 008390}$ & Interferon regulatory factor 1 & 7.60 \\
Mapk3 & NM 011952 & Mitogen activated protein kinase 3 & 5.84 \\
Tnfsf14 & $\underline{\text { NM 019418 }}$ & Tumor necrosis factor (ligand) & 17.71 \\
Traf3 & superfamily, member 14 & 3.38 \\
\hline
\end{tabular}

LPS $(1 \mu \mathrm{g} / \mathrm{ml})$ did not have any effect on these genes.

with LPS $(1 \mu \mathrm{g} / \mathrm{mL})$ produced an increase in NFKB translocation (p65 subunit) to the nuclear compartment that was evident at 45 mins of incubation time. Figure 2A, 2B and $2 \mathrm{C}$ show that this translocation process was inhibited in MyD88-KO, TRIF-KO and Wild-type macrophages by pretreatment with triptolide in a dose dependent manner. Similarly, triptolide inhibited the gene expression of COX-2 and iNOS induced by LPS in MyD88-KO, TRIF$\mathrm{KO}$ and Wild-type macrophages in a dose dependent manner (Figure 3A, 3B and $3 \mathrm{C}$ ). Together, these results demonstrate that triptolide suppresses both MyD88 and TRIF -dependent signaling pathways.

\section{Effect of triptolide activity on protein and mRNA expression of adaptor molecules and TLR}

Triptolide was found to suppress both MyD88 and TRIFdependent signaling pathways activated by LPS agonization of TLR4. (Figures 2,3). Therefore, to further charac- terize the role of triptolide in the signaling events triggered by LPS in macrophages upstream of $N F k B$, we studied the expression of adapter molecules TRIF and MyD88 as well as that of TLR4 receptor at mRNA and protein levels. Triptolide treatment suppressed the mRNA and protein levels of LPS-induced TLR4 (Figure 5) and TRIF (Figure 4) expression but not MyD88 (data not shown). Suppression of poly I:C induced TLR3 mRNA expression by triptolide, the only TRIF specific toll-like receptor, has not been observed by qRT-PCR (data not shown). Together these observations suggest that triptolide inhibition of $\mathrm{NF} \mathrm{KB}$ may be directed from the receptor level for MyD88 pathway and from the adapter level for TRIF pathway.

\section{Discussion}

Past studies have demonstrated that triptolide can induce anti-inflammatory responses in several assay systems 
Table 4: Fold changes in gene expression in cells treated with LPS ( $1 \mu \mathrm{g} / \mathrm{ml})$ as compared to endogenous expression levels in untreated cells.

\begin{tabular}{|c|c|c|c|}
\hline Gene symbol & Accession No. & Gene name & Fold change in response to LPS \\
\hline C3 & NM 009778 & Complement component 3 & 3.02 \\
\hline$\| 15$ & NM 008357 & Interleukin 15 & 6.39 \\
\hline Ltb & NM 008518 & Lymphotoxin B & 4.48 \\
\hline Atf1 & NM 007497 & Activating transcription factor 1 & 4.43 \\
\hline $\mathrm{Bcl} 10$ & NM 009740 & B-cell leukemia/lymphoma 10 & 22.13 \\
\hline Cflar & $\underline{\text { NM } 009805}$ & $\begin{array}{l}\text { CASP8 and FADD-like apoptosis } \\
\text { regulator }\end{array}$ & 14.01 \\
\hline Edg2 & NM 010336 & $\begin{array}{l}\text { Endothelial differentiation, } \\
\text { lysophosphatidic acid G-protein- } \\
\text { coupled receptor, } 2\end{array}$ & 6.49 \\
\hline Relb & NM 009046 & $\begin{array}{l}\text { Avian reticuloendotheliosis viral (v-rel) } \\
\text { oncogene related B }\end{array}$ & 21.38 \\
\hline Stat1 & NM 009283 & $\begin{array}{l}\text { Signal transducer and activator of } \\
\text { transcription } 1\end{array}$ & 5.89 \\
\hline $\mathrm{Cd} 40$ & NM 011611 & Cluster of Differentiation 40 & 112.83 \\
\hline $\mathrm{Nr} 2 \mathrm{c} 2$ & NM 011630 & $\begin{array}{l}\text { Nuclear receptor subfamily } 2 \text {, group } C \text {, } \\
\text { member } 2\end{array}$ & -4.07 \\
\hline Peli1 & NM 030015 & Pellino 1 & 5.48 \\
\hline
\end{tabular}

Triptolide $(55.5 \mathrm{nM})$ did not have any effect on these genes.

$[14,23]$. However, the direct molecular targets of triptolide have remained elusive. In our previous report, we showed that triptolide significantly inhibited the secretion of inflammatory cytokines that occurred with RAW 264.7 cells when stimulated with LPS [13]. Subsequently, we performed a gene array analysis (Tables $2,3,4$ ) to elucidate additional members of the immune signaling cascade that could be potential targets of triptolide activity. The results of this analysis showed that 44 genes, which were known to regulate inflammation were differentially expressed in stimulated RAW 264.7 cells following triptolide treatment. These 44 genes represented key immune signaling pathways such as TLR signaling, MAPK signaling, Jak-STAT signaling and cytokinecytokine receptor interaction. In our present study we undertook further investigation on cellular mechanism of triptolide activity that focused on TLRs, given their upstream location in the immune signaling cascade and their increasingly recognized importance in inflammatory and autoimmune diseases [24].

LPS induces TLR4 dimerization to trigger the activation of downstream signaling pathways $[25,26]$. This receptor dimerization activates transcription factor $\mathrm{NF} K \mathrm{~B}$, leading to the induction of inflammatory gene products such as COX-2 and iNOS $[25,26]$. Many studies have demonstrated that triptolide and its synthetic derivatives inhibited NFKB activation induced by TLR4 agonist
LPS [13,14,27] but effect of triptolide on any TLR expression was never reported. The present study shows that triptolide suppressed ligand (LPS)-induced expression of TLR4 at mRNA and protein levels (Figure 5). We also observed for the first time that triptolide suppressed Poly(I:C) (TLR3 agonist) and Zymosan (TLR2 agonist) induced expression of COX-2 and iNOS (Figure 1A, B). These observations suggest that triptolide may offer protection against wide range of infections that occurs by different TLR inductions.

The TLR-ligand activities are transduced through specific intracellular adaptor molecules, most notably MyD88 and TRIF. The importance of MyD88 and TRIF lies in finding that each leads to a distinct profile of immune mediators that in turn determines the phenotype of the cells that primarily are responsible for the development of adaptive immune responses [1-4]. By studying the expression of well-characterized cytokine/ chemokine target genes downstream of MyD88 (e.g., CCL3) and TRIF (e.g., IRG-1) [21,22] we demonstrated differential regulation exerted by triptolide in ligandinduced 264.7 RAW macrophages. We observed that triptolide downregulated the expression of both MyD88dependent cytokine such as CCL3 induced by MyD88dependent ligands (Zymosan/TLR2 ligand, LPS/TLR4) and TRIF-dependent cytokine IRG-1 (Poly I:C/TLR3 and LPS/TLR4) in a concentration dependent manner (Figure 


\section{A. Zymosan stimulation}

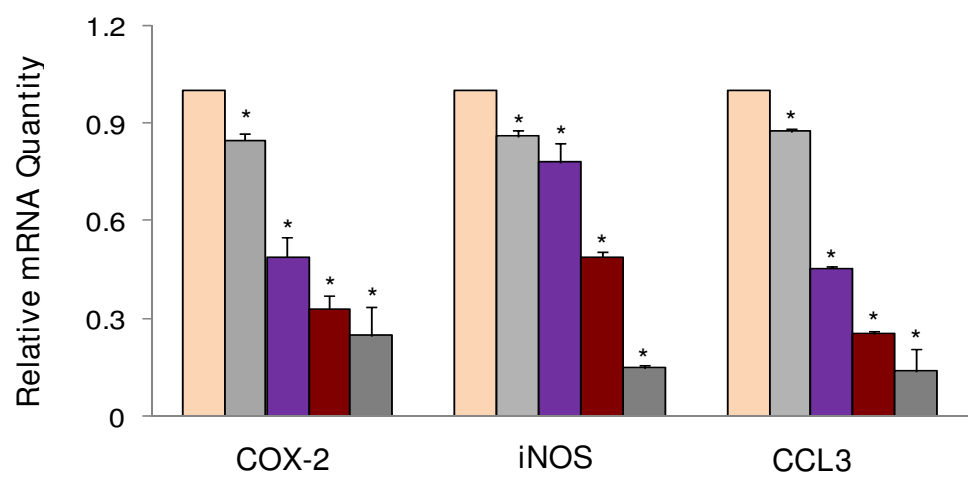

B. Poly I:C stimulation

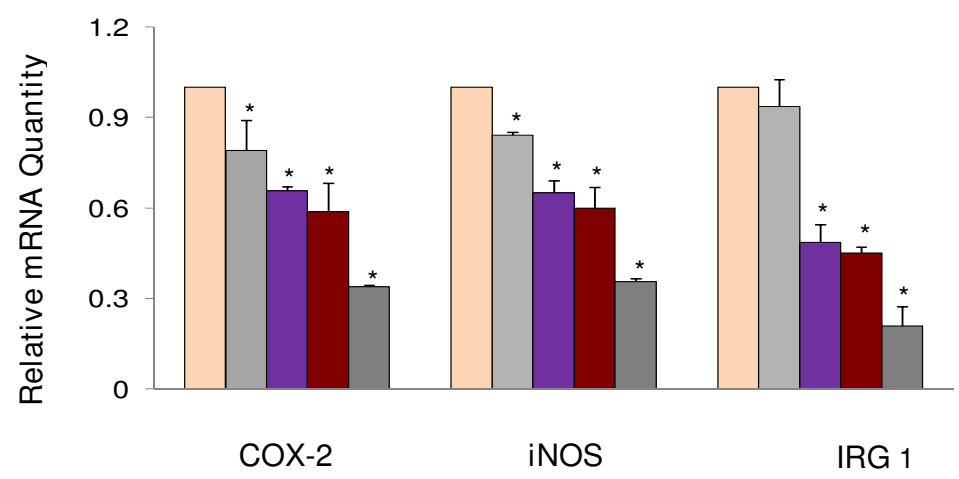

C. LPS stimulation

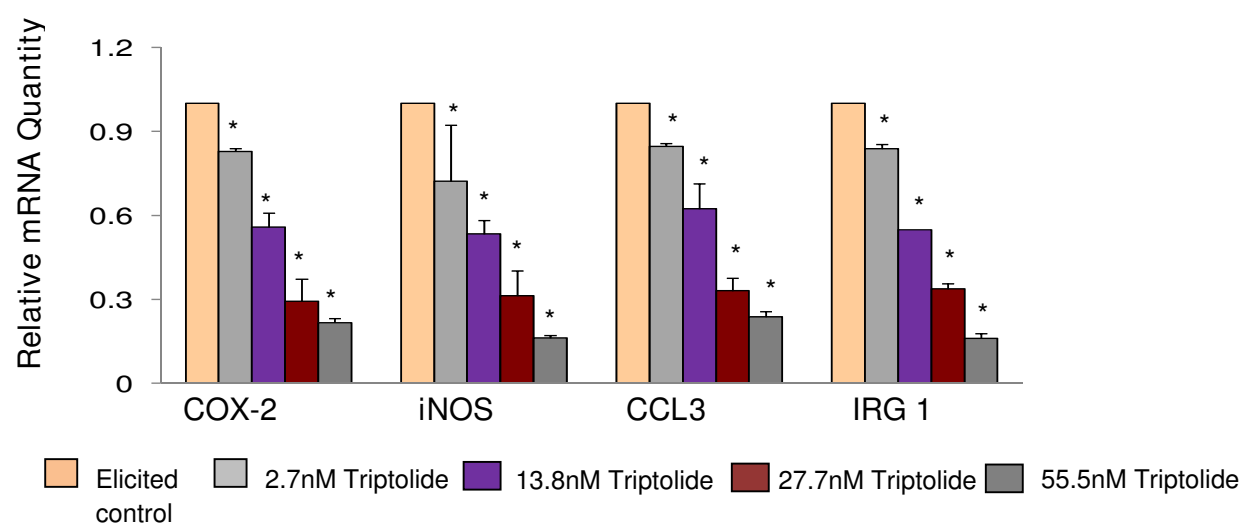

Figure 1 Effect of triptolide on gene expression of COX-2, iNOS and chemokines in response to various TLR ligand activation in RAW macrophages. The effect of triptolide treatment (three replicates) on a specific gene expression was measured by the mRNA quantity relative to the response to ligand activation only (positive control) that was normalized to a value of 1.00; lower values represent greater inhibitory effects with 0.00 corresponding to a complete inhibition of the induced gene expression. The value of the negative control (no induction) was normalized to 0.00 . Values are mean \pm S.D. ${ }^{*}, p<0.05$; (post-ANOVA comparison with Ligand-treated positive control). A. Effect of triptolide on mRNA levels of COX-2, iNOS and CCL3 following zymosan stimulation. B. Effect of triptolide on mRNA levels of COX-2, iNOS, and IRG-1 following Poly I:C stimulation. C. Effect of triptolide on mRNA levels of COX-2, iNOS, CCL3 and IRG-1 following LPS stimulation. 
A. NFKB - MyD88 KO
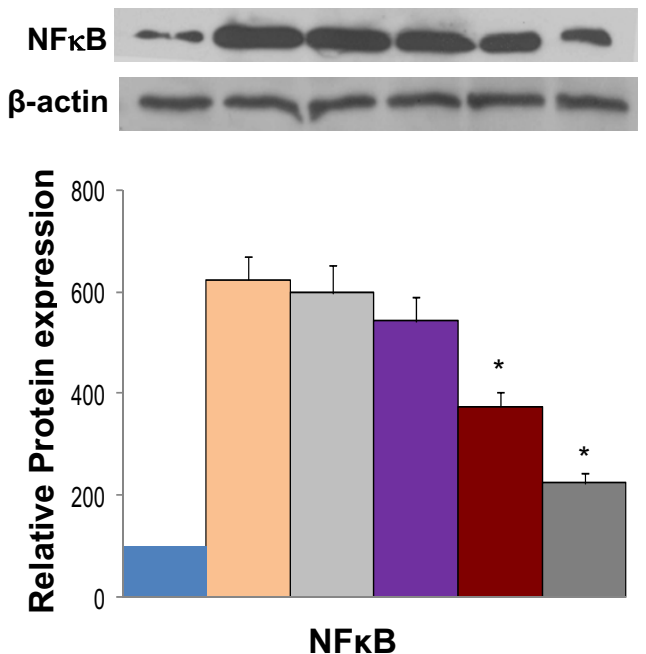

B. NFKB - TRIF KO

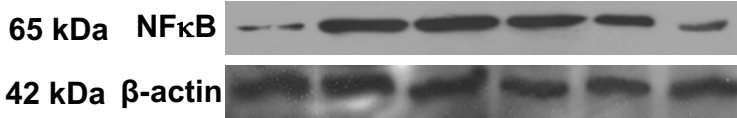

$65 \mathrm{kDa}$

$42 \mathrm{kDa}$

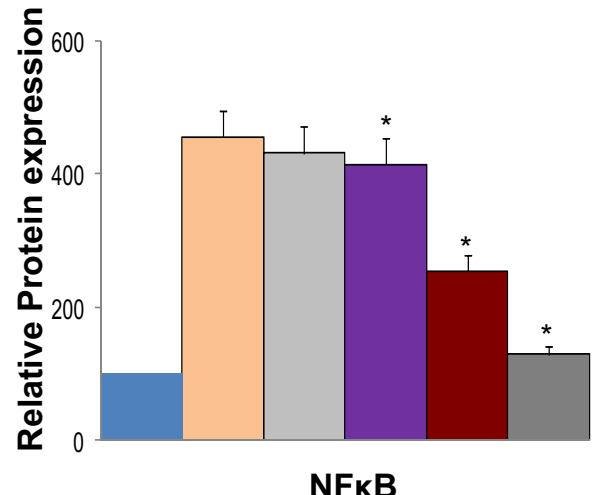

\section{NFKB - WT}
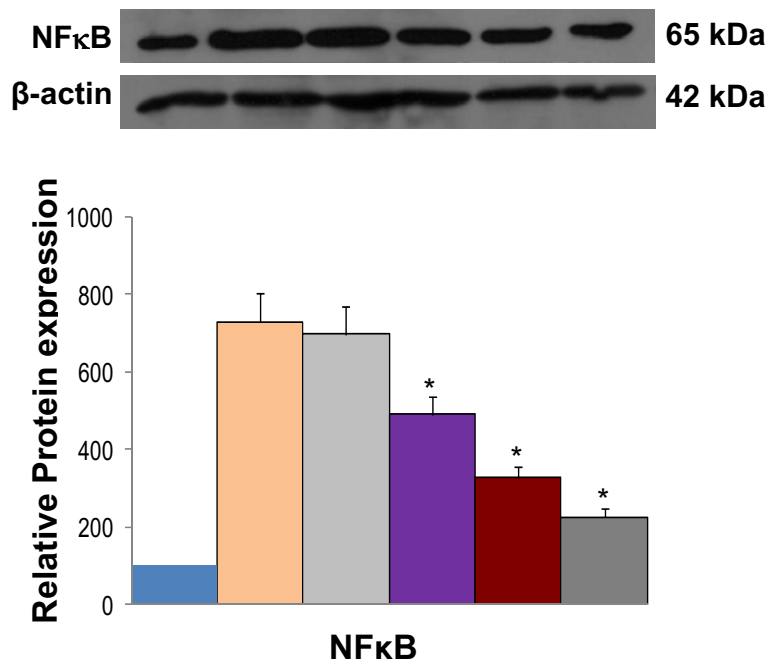

Negative control $\Delta$

Elicited control

2.7nM Triptolide

13.8nM Triptolide

27.7nM Triptolide

55.5nM Triptolide

Figure 2 Effect of triptolide on NFKB p65 nuclear translocation. Representative immunoblots of NFkB (p65). $\beta$-actin used as internal control. The protein expression was measured by densitometric analysis (Total Labs software $v$ 2.01). The untreated control T-was normalized to a value of 100. Each value represents mean \pm SD of three experiments performed in triplicate. A. Effect of triptolide on NFKB translocation in MyD88KO RAW macrophages B. Effect of triptolide on NFkB translocation in TRIFKO RAW macrophages C. Effect of triptolide on NFkB translocation in Wild-type RAW macrophages. * Significantly different from control $(p<0.05)$ ANOVA followed by LSD

1A, 1B and 1C). To further confirm that both MyD88 and TRIF mediated signaling are involved in triptolide activity, we showed that triptolide suppressed the NFKB translocation (p65 molecule) to the nucleus and also the downstream expression of COX-2 and iNOS mRNA in
MyD88 KO (when only TRIF is present) and TRIF-KO (when only MyD88 is present) macrophages as well as in wild-type macrophages induced with TLR specific ligand, LPS (Figure 2 and 3). These results show that inhibition of NFKB activation and COX-2 and iNOS expression by 


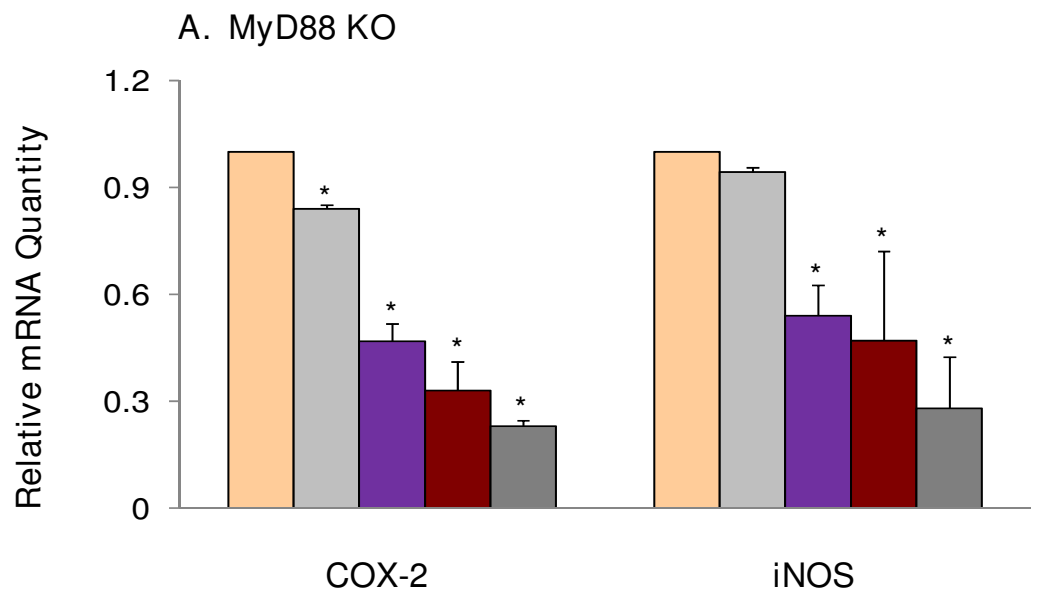

\section{B. TRIF KO}

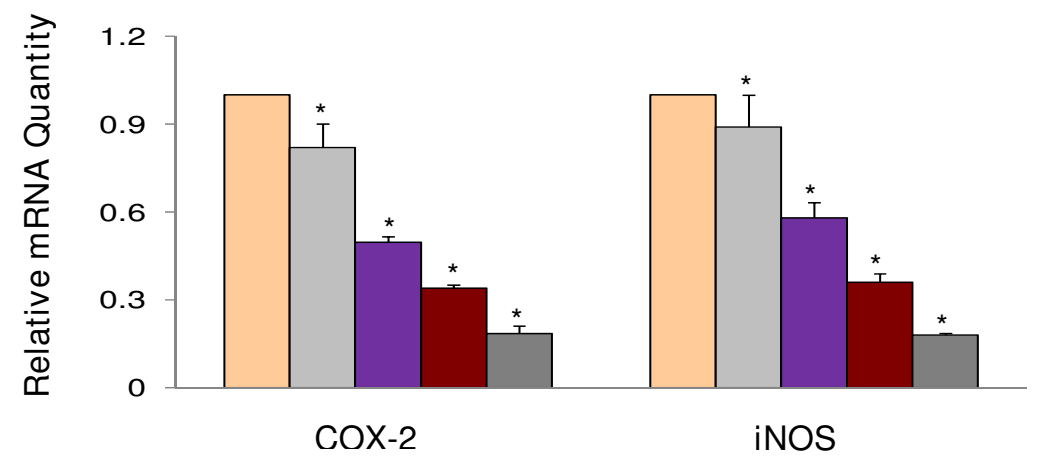

\section{TLR4 Wild type}

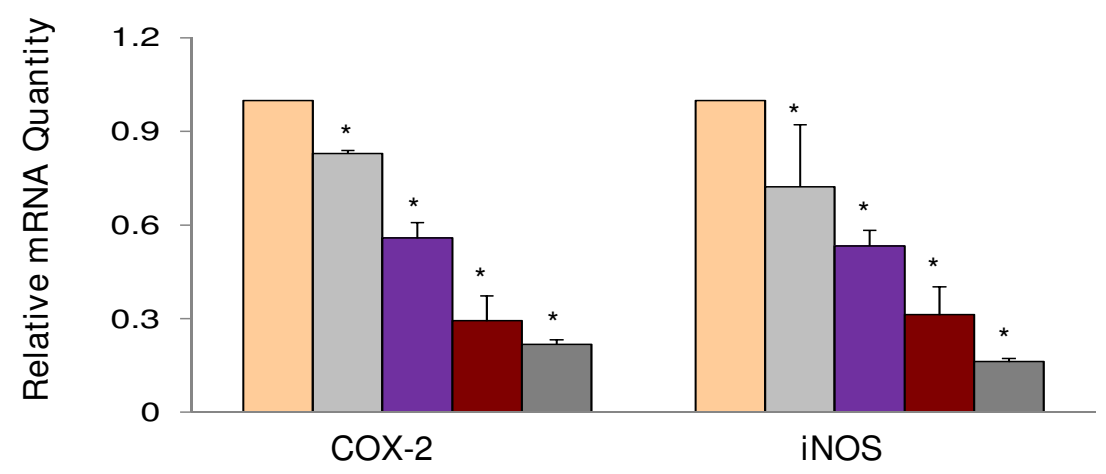

\section{Elicited $\square$ 2.7nM Triptolide $\square$ 13.8nM Triptolide $\square$ 27.7nM Triptolide $\square$ 55.5nM Triptolide} control

Figure 3 Effect of triptolide on gene expression of COX-2 and iNOS (mean \pm S.D). The expression of specific genes was measured by the mRNA quantity relative to the response to LPS activation (positive control) that was normalized to a value of 1.00; lower values represent greater inhibitory effects with 0.00 corresponding to a complete inhibition of the induced gene expression. The value of the negative control (no induction) was normalized to 0.00. A. Expression of COX-2 and iNOS genes in MyD88KO macrophages; B. Expression of COX-2 and iNOS genes in TRIFKO macrophages; C. Expression of COX-2 and iNOS genes in WT macrophages. * Significantly different from control $(p<0.05)$ ANOVA followed by LSD. 
A. TRIF mRNA expression

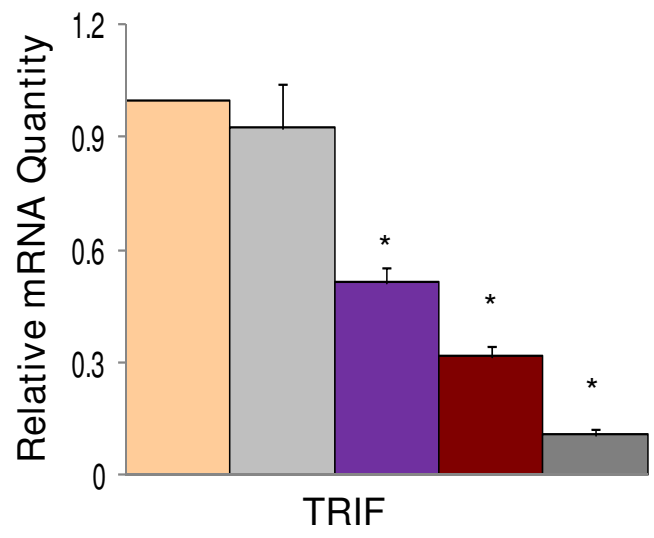

Negative control $\Delta$

13.8nM Triptolide

\section{B. TRIF Protein expression}

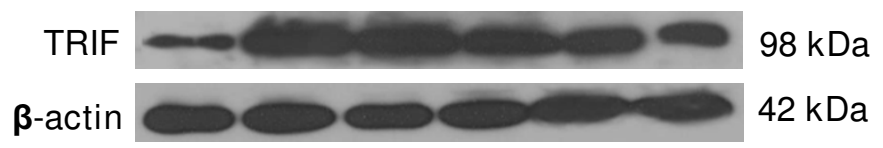

C. Densitometric Analysis

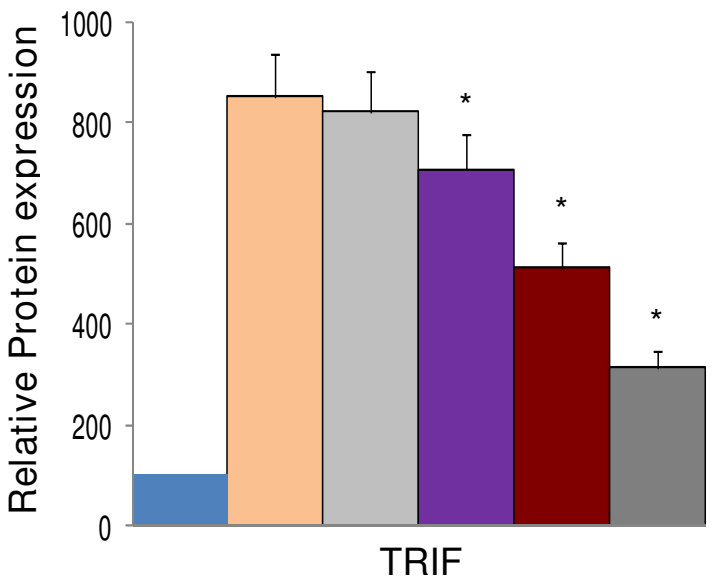

2.7nM Triptolide

27.7nM Triptolide

Figure 4 Effect of triptolide on mRNA and protein expression of TRIF (mean \pm S.D). The mRNA expression of TRIF was measured by the mRNA quantity relative to the response to LPS activation (positive control) that was normalized to a value of 1.00; lower values represent greater inhibitory effects with 0.00 corresponding to a complete inhibition of the induced gene expression. The value of negative control (no induction) was normalized to 0.00. A. mRNA expression of TRIF; B. Protein expression of TRIF; C. Densitometric analysis for protein expression. * Significantly different from control $(p<0.05)$ ANOVA followed by LSD.

triptolide could be achieved in presence of MyD88 or TRIF alone or when both are present as in wild type macrophages. These results also suggest that triptolide can block both MyD88- and TRIF-dependent pathways that lead to NFkB transactivation. Since MyD88 and TRIF are the only adapters exclusively mediating all TLR signaling, it is possible that triptolide may suppress wide-range of TLR signaling through other TLRs in addition to TLR4. Although in the current study we focused on TLR4 pathway, our gene array data (Tables a2a and a3a) as well as the observations presented in Figure 1A and 1B may support the suggestion that triptolide has activities against other TLRs. When the changes in the expression of TRIF and MyD88 in response to triptolide were tested (Figure 4), triptolide inhibited the mRNA and protein expression of TRIF, but not MyD88 in a dose dependent manner. A study by Yamamoto et al. (2003) [28] using TRIF knock- out mice has revealed that TRIF is physiologically essential for TLR-3 mediated signaling and that TRIF is involved in the LPS-induced MyD88-independent pathway.

Triptolide blocked early signaling pathways of TLRs suggesting that its inhibitory action was at the receptor and adapter molecule levels. Thus, a direct interaction of triptolide with TLR4 may be hypothesized. This study suggests that plant compounds, such as triptolide, can modulate TLR-mediated inflammatory responses and can reduce the risk of chronic diseases, associated with exaggerated TLR activation. Macrophages are the key antigen presenting cells in the pathogenesis of RA and involvement of TLR4 has been shown to play role in joint destruction in RA [29]. Therefore, the present study showing interaction of triptolide with components of TLR signaling, such as TLR4, are particularly relevant 
A. TLR-4 mRNA expression

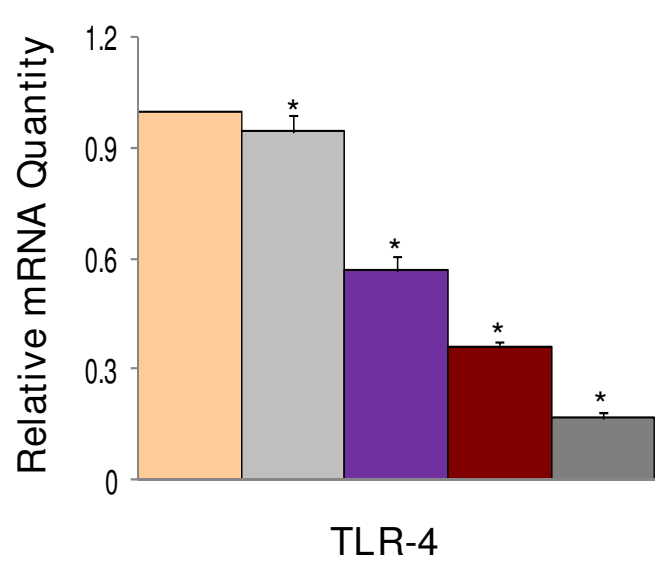

\section{B. TLR-4 Protein expression}
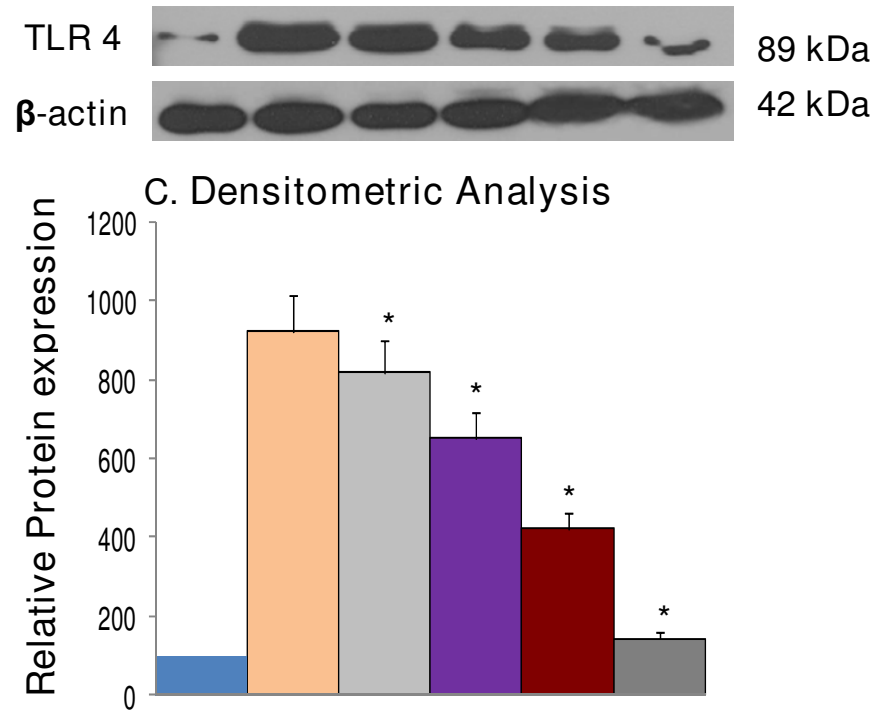

TLR-4

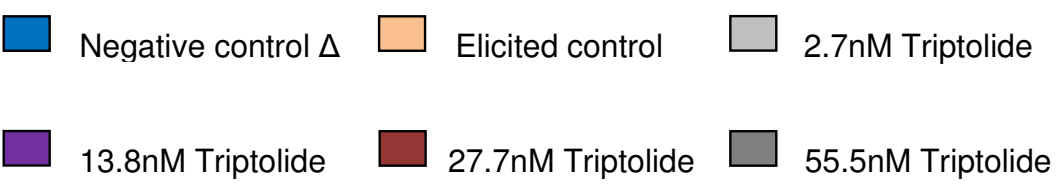

Figure 5 Effect of triptolide on mRNA and protein expression of TLR 4 (mean \pm S.D.). The mRNA expression of TLR 4 was measured by the mRNA quantity relative to the response to LPS activation (positive control) that was normalized to a value of 1.00; lower values represent greater inhibitory effects with 0.00 corresponding to a complete inhibition of the induced gene expression. The value of negative control (no induction) was normalized to 0.00 . A. mRNA expression of TLR 4; B. Protein expression of TLR 4; C. Densitometric analysis for protein expression. * Significantly different from control $(p<0.05)$ ANOVA followed by LSD

and support the recent promise shown in clinics against RA by botanical extracts containing triptolide [30,31].

\section{Conclusions}

The results from the present study suggest that the suppression of agonist-induced NFKB activation and chemokine expression by triptolide is mediated by targeting the early signaling of TLRs, particularly that of TLR4 in RAW 264.7 cells. Triptolide downregulated the expression of TLR4 proteins and that of TRIF adapter proteins in the MyD88-independent pathway of TLR4. In addition gene expression profiles in response to triptolide treatment in stimulated macrophages suggest that triptolide may have multiple cellular targets contributing to its strong anti-inflammatory and immune suppressive properties.

\section{Author information}

MD, VGP and IR have a Ph.D in Biology or related fields as their highest obtained degree. RD has a M.S. in Horticulture and is currently studying towards her MBA. MD was formerly an Assistant Research Professor at the Biotechnology Center at Rutgers University, NJ and currently an Associate Professor in the Nutrigenomics Program, South Dakota state University, SD. MD specializes in Molecular Biology. VGP was formerly a Postdoctoral Associate at Rutgers University and is currently working as a Postdoctoral Researcher at University of Cincinnati, $\mathrm{OH}$. RD is a Senior Laboratory Technician in IR's group at Rutgers University, NJ. IR is a Professor in the Department of Plant Biology and Pathology at Rutgers University, NJ. 


\section{Abbreviations}

COX-2: Cycloxygenase-2; iNOS: inducible Nitric oxide synthase; IRG: Interferon regulating gene; LPS: Lipopolysaccharide; MyD88: Myeloid differentiation 88; NFkB: Nuclear factor kappa B; Poly I:C: polyinosinic:polycytidylic acid; TLRs: Toll like Receptors; TRIF: TIR-domain-containing adapter-inducing interferon- $\beta$; CCL3: Chemokine (C-C motif) ligand 3.

\section{Authors' contributions}

MD conceived of the study, designed all experiments, carried out, analyzed and interpreted gene array experiments and data. MD also wrote part of the manuscript. VGP carried out rest of the experiments, analyzed his part of data and helped with drafting the manuscript. VGP also interpreted his analyzed data in consultation with MD. RD participated in real-time PCR experiments and helped in proof reading the manuscript for English grammar. IR provided facilities within his laboratory for all experiments at Rutgers University. IR also provided critical comments on the manuscript. All authors read and approved the final manuscript.

\section{Acknowledgements}

The authors would like to thank Reneta Pouleva for her excellent technical support.

Funding for this work came from Phytomedics, Inc., Jamesburg, NJ to IR and by National Institute of Health (NIH) Pathway to Independence award [Grant K99AT004245 and 4R00AT004245] to MD. Additional funding sources are (to IR): NIH Center for Dietary Supplements Research on Botanicals and Metabolic Syndrome [Grant 1-P50 AT002776-01], NIH [Grant U01 TW006674] for ICBG. VGP and RD were supported in part or in full by the grants listed above.

\section{Author Details}

${ }^{1}$ Cancer and Cell Biology Department, University of Cincinnati, OH 45219, USA, 2Nutrigenomics Program, South Dakota State University, Brookings, SD 57007, USA and ${ }^{3}$ Biotech Center, Rutgers University, 59 Dudley Rd, New Brunswick, NJ 08901, USA

Received: 18 November 2009 Accepted: 12 April 2010

Published: 12 April 2010

\section{References}

1. Cook DN, Pisetsky DS, Schwartz DA: Toll-like receptors in the pathogenesis of human disease. Nat Immunol 2004, 5:975-979.

2. Michelsen KS, Wong MH, Shah PK, Zhang W, Yano J, Doherty TM, Akira S, Rajavashisth TB, Arditi M: Lack of Toll-like receptor 4 or myeloid differentiation factor 88 reduces atherosclerosis and alters plaque phenotype in mice deficient in apolipoprotein E. Proc Natl Acad Sci USA 2004, 101:10679-10684

3. Bjorkbacka H, Kunjathoor W, Moore KJ, Koehn S, Ordija CM, Lee MA, Means T, Halmen K, Luster AD, Golenbock DT, Freeman MW: Reduced atherosclerosis in MyD88-null mice links elevated serum cholesterol levels to activation of innate immunity signaling pathways. Nat Med 2004, 10:416-421

4. Takeda K, Akira S: Toll-like receptors. Curr Protoc Immunol 2007, Chapter 14(Unit 14):12.

5. Foster SL, Hargreaves DC, Medzhitov R: Gene-specific control of inflammation by TLR-induced chromatin modifications. Nature 2007 447:972-978.

6. O'Neill LA: Targeting signal transduction as a strategy to treat inflammatory diseases. Nat Rev Drug Discov 2006, 5:549-563.

7. Pandey S, Agrawal DK: Immunobiology of Toll-like receptors: emerging trends. Immunol Cell Biol 2006, 84:333-341.

8. Amati L, Pepe M, Passeri ME, Mastronardi ML, Jirillo E, Covelli V: Toll-like receptor signaling mechanisms involved in dendritic cell activation: potential therapeutic control of T cell polarization. Curr Pharm Des 2006, 12:4247-4254

9. Dabbagh K, Lewis DB: Toll-like receptors and T-helper-1/T-helper-2 responses. Curr Opin Infect Dis 2003, 16:199-204.

10. Parker LC, Prince LR, Sabroe I: Translational mini-review series on Toll-like receptors: networks regulated by Toll-like receptors mediate innate and adaptive immunity. Clin Exp Immuno/ 2007, 147:199-207.

11. Fujihara M, Muroi M, Tanamoto K, Suzuki T, Azuma H, Ikeda H: Molecular mechanisms of macrophage activation and deactivation by lipopolysaccharide: roles of the receptor complex. Pharmacol Ther 2003, 100:171-194.
12. Lipsky PE, Tao XL: A potential new treatment for rheumatoid arthritis: thunder god vine. Semin Arthritis Rheum 1997, 26:713-723.

13. Ma J, Dey M, Yang H, Poulev A, Pouleva R, Dorn R, Lipsky PE, Kennelly EJ, Raskin I: Anti-inflammatory and immunosuppressive compounds from Tripterygium wilfordii. Phytochemistry 2007, 68:1172-1178.

14. Gong Y, Xue B, Jiao J, Jing L, Wang X: Triptolide inhibits COX-2 expression and PGE2 release by suppressing the activity of NF-kappaB and JNK in LPS-treated microglia. J Neurochem 2008, 107:779-788.

15. Karin M, Yamamoto $Y$, Wang QM: The IKK NF- kappa B system: a treasure trove for drug development. Nat Rev Drug Discov 2004, 3:17-26.

16. Chang WT, Kang JJ, Lee KY, Wei K, Anderson E, Gotmare S, Ross JA, Rosen GD: Triptolide and chemotherapy cooperate in tumor cell apoptosis. A role for the $\mathrm{p} 53$ pathway. J Bio/ Chem 2001, 276:2221-2217.

17. Toubi E, Shoenfeld Y: Toll-like receptors and their role in the development of autoimmune diseases. Autoimmunity 2004 37:183-188.

18. Dey M, Ribnicky D, Kurmukov AG, Raskin I: In vitro and in vivo antiinflammatory activity of a seed preparation containing phenethylisothiocyanate. J Pharmacol Exp Ther 2006, 317:326-333.

19. Huang H, Park CK, Ryu JY, Chang EJ, Lee Y, Kang SS, Kim HH: Expression profiling of lipopolysaccharide target genes in RAW264.7 cells by oligonucleotide microarray analyses. Arch Pharmacol Res 2006, 29:890-897

20. Krakauer T: Molecular therapeutic targets in inflammation: cyclooxygenase and NF-kappaB. Curr Drug Targets Inflamm Allergy 2004, 3:317-324.

21. Fujihara M, Muroi M, Tanamoto K, Suzuki T, Azuma H, Ikeda H: Molecular mechanisms of macrophage activation and deactivation by lipopolysaccharide: roles of the receptor complex. Pharmacol The 2003, 100:171-194.

22. Akira S, Takeda K, Kaisho T: Toll-like receptors: critical proteins linking innate and acquired immunity. Nature Immunology 2001, 2:675-680.

23. Jiao J, Xue $B$, Zhang $L$, Gong $Y$, Li K, Wang $H$, Jing $L$, Xie J, Wang X: Triptolide inhibits amyloid-beta1-42-induced TNF-alpha and IL-1 beta production in cultured rat microglia. J Neuroimmunol 2008, 205:32-36.

24. Kawai T, Takeuchi O, Fujita T, Inoue J-i, Mühlradt FP, Sato S, Hoshino K, Akira S: Lipopolysaccharide Stimulates the MyD88-Independent Pathway and Results in Activation of IFN-Regulatory Factor 3 and the Expression of a Subset of Lipopolysaccharide-Inducible Genes. J Immunol 2001, 167:5887-5894.

25. Pindado J, Balsinde J, Balboa MA: TLR3-Dependent Induction of Nitric Oxide Synthase in RAW 264.7 Macrophage-Like Cells via a Cytosolic Phospholipase $\mathrm{A}_{2}$ /Cyclooxygenase-2 Pathway. J Immunol 2007 , 179:4821-4828.

26. Youn HS, Lim HJ, Lee HJ, Hwang D, Yang M, Jeon R, Ryu JH: Garlic (Allium sativum) extract inhibits lipopolysaccharide-induced Toll-like receptor 4 dimerization. Biosci Biotechnol Biochem 2008, 72:368-375.

27. Liu Q, Chen T, Chen G, Li N, Wang J, Ma P: Immunosuppressant triptolide inhibits dendritic cell-mediated chemoattraction of neutrophils and $T$ cells through inhibiting Stat3 phosphorylation and NF-kappaB activation. Biochem Biophys Res Commun 2006, 345:1122-1130.

28. Yamamoto M, Sato S, Hemmi H, Hoshino K, Kaisho T, Sanjo H, Takeuchi O, Sugiyama M, Okabe M, Takeda K, Akira S: Role of adaptor TRIF in the MyD88-independent toll-like receptor signaling pathway. Science 2003, 301:640-643.

29. Huang Q, Ma Y, Adebayo A, Pope RM: Increased macrophage activation mediated through toll-like receptors in rheumatoid arthritis. Arthritis Rheum 2007, 56:2192-2201.

30. Schmidt BM, Ribnicky DM, Lipsky PE, Raskin I: Revisiting the ancient concept of botanical therapeutics. Nat Chem Biol 2007, 3:360-366.

31. Goldbach R, Wilson M, Fleischmann R, Olsen N, Silverfield J, Kempf P, Kivitz A, Sherrer Y, Pucino F, Csako G, Costello R, Pham TH, Snyder C, Heijde D van der, Tao X, Wesley R, Lipsky PE: Comparison of Tripterygium wilfordii Hook $F$ versus sulfasalazine in the treatment of rheumatoid arthritis: a randomized trial. Ann Intern Med 2009, 151:229-40.

doi: 10.1186/1472-6769-10-3

Cite this article as: Premkumar et al., MyD88-dependent and independent pathways of Toll-Like Receptors are engaged in biological activity of Triptolide in ligand-stimulated macrophages BMC Chemical Biology 2010, 10:3 